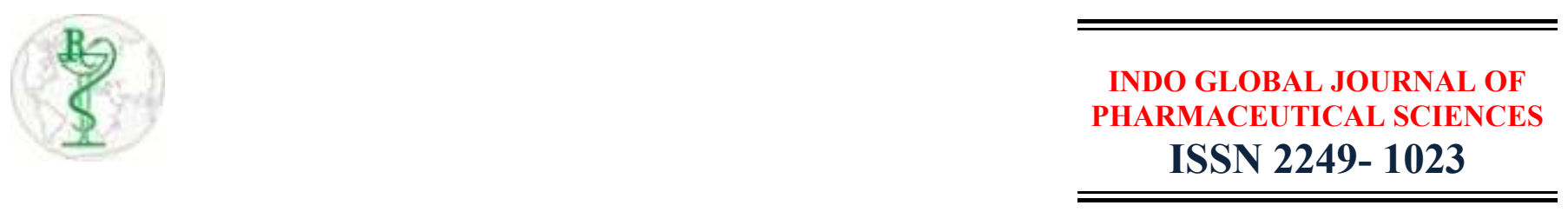

\title{
Facile Synthesis of Biocompatible Iron Oxide Magnetic Nanoparticles
}

\author{
Ragini Raghav ${ }^{1,2}$, Dibya R. Jha ${ }^{1}$, Sudha Srivastava ${ }^{1 *}$ \\ ${ }^{I}$ Department of Bioetchnology, Jaypee Institute of Information Technology, A-10, Sec 62, Noida 201307, Uttar Pradesh, India \\ ${ }^{2}$ Department of Biotechnology, Shree M \& N Virani Science College, Kalawad Road, Rajkot-360005, Gujarat, India
}

Address for Correspondence: Sudha Srivastava, $\underline{\text { sudha.srivastava@jiit.ac.in }}$

Keywords

Magnetic

Nanoparticles;

Biocompatible; Coprecipitation.
ABSTRACT: In the present study, magnetite $\left(\mathrm{Fe}_{3} \mathrm{O}_{4}\right)$ nanoparticles were synthesized by modified coprecipitation method employing ferrous/ferric mixed salt-solution inalkaline conditions (ration 1:1). The surface of magnetic nanoparticles was coated with trisodium citrate facilitating charge stabilization. The $\mathrm{Fe}_{3} \mathrm{O}_{4}$ nanoparticles displayed magnetic properties and were well dispersed in water. The magnetite nanoparticles were characterized by scanning electron microscopy (SEM) and UV-visible spectroscopy. Cup borer method was performed to evaluate the biocompatibility of magnetite nanoparticles employing Micrococcus luteus and Bacillus licheniformis as model microorganisms. Further, the effect of different concentrations of magnetic nanoparticles was also evaluated over these microbial strains. The results displayed that the synthesized $\mathrm{Fe}_{3} \mathrm{O}_{4}$ nanoparticles displayed biocompatibility even at high concentrations. (C) 2016 iGlobal Research and Publishing Foundation. All rights reserved.

Conference Proceedings: International Conference on Advances in Plant and Microbial Biotechnology (PMB2017); JIIT, Noida: February 02-04, 2017

Indo Global Journal of Pharmaceutical Sciences( ISSN 22491023 ; CODEN- IGJPAI; NLM ID: 101610675) indexed and abstracted in EMBASE(Elsevier), SCIRUS(Elsevier),CABI, CAB Abstracts, Chemical Abstract Services(CAS), American Chemical Society(ACS), Index Copernicus, EBSCO, DOAJ, Google Scholar and many more. For further details, visit http://iglobaljournal.com 